\title{
Reflexões sobre o fazer cinematográfico: a ética como bússola para uma nova cartografia do cinema mundial'
}

\author{
Contemplating filmmaking: ethics as a compass for a new \\ cartography of world cinema
}

\author{
Ana Paula Martins Gouveia I \\ Universidade de São Paulo \\ Escola Superior Artística do Porto (ESAP)
}

\section{Resumo}

Este artigo se dispõe a fazer uma breve reflexão sobre o filme "O Grande Silêncio” de Philip Gröning e a conexão que o mesmo estabelece com a questão ética do fazer cinematográfico; sendo a ética aqui entendida como um campo de investigaçáo sobre os meios de se alcançar a felicidade. $O$ filme de Gröning se destaca triplamente dentro desta reflexão, ao se pensar a ética (ethos) enquanto conduta, local físico e temática do filme.

Palavras-Chave: Ética; cinema; filosofia.

\section{Abstract}

This article intends to do a brief reflection on the film "Into the Great Silence" by Philip Gröning and its connection with Ethics in ancient philosophy. The film stands out in three specific ways considering this analyzes; Firstly in terms of ethical conduct; Secondly, thinking about "ethos" as "dwelling", or "living place"; And thirdly by the very thematic of the film, which is nothing but the very search for happiness and the attempt to understand how it can be achieved.

Keywords: Ethics; film; philosophy.

1 Este artigo foi originalmente pensado como uma apresentação oral no XVI Encontro Socine, na sessão: Por uma Filosofia do Cinema, em 2012. 


\section{Introdução}

De maneira abrangente, ao tentarmos entender o que efetivamente é uma cartografia, podemos nos referir a ela como a arte de representar uma determinada superfície, ou campo de investigação, através de algum tipo de código expressivo. De forma mais específica, a designação de cartografia, tal qual introduzida no século XIX, foi criada pela associação da palavra às cartas utilizadas para a localização, dentre as quais era possível distinguir as cartas geográficas, que delineiam os contornos dos continentes, e as cartas náuticas que, para além de nos mostrar esses contornos, também ofereciam indicaçóes para a orientação dos navegadores.

Para este estudo, gostaria de pensar na cartografia do cinema mundial de uma forma mais ligada a estas antigas cartas náuticas, que também serviam como uma forma de orientação aos navegadores, mais do que um desenho preciso dos contornos da geografia; isto é, mais do que uma forma de "localização" das novas produçóes cinematográficas, gostaria de sugerir um exemplo que possa nos servir como guia. Para refletir sobre este sentido de bússola, e não de contorno, foi pensado um modelo específico de universo fílmico, onde era possível encontrar uma forma de orientação que se desdobrasse em vários aspectos da ética do fazer cinema. Foi selecionado, então, o quinto filme do cineasta alemão Philip Gröning, "O Grande Silêncio" (Die Grosse Stille), que parece trazer consigo um indicativo do proceder cinematográfico, o qual penso ser fundamental para que uma nova cartografia do cinema mundial, calcada na ética, possa ser traçada.

O filme O Grande Silêncio pareceu-me singularmente significativo para abordar aquilo que acredito ser uma questão fundamental não só ligada ao cinema, mas a todo universo das contemplaçôes e práticas humanas - a ética; sendo que aqui a ética é entendida como o estudo sobre os meios de se alcançar a felicidade e também um campo de investigação sobre o que significa a felicidade.

Com este intuito, refletiremos em primeiro lugar sobre o fato de Gröning dar um exemplo de conduta ética, pelo modo como se comporta ao longo de todo o trabalho, desde o momento em que decide filmar o mosteiro, até o momento em que o finaliza e, principalmente, as razóes que o motivaram à escolha do tema. Em um segundo momento, falaremos sobre "ethos" enquanto morada, e aqui se fará uma investigação sobre o ambiente filmado enquanto elemento do enunciado, e a sua posterior enunciação que cria uma nova morada para o espectador. Em terceiro lugar, penetraremos na temática do filme, no caminho percorrido, e em como a busca do diretor se concilia, de alguma forma, com a busca dos monges ali retratados; e esta busca da felicidade, enquanto componente ético, também se reflete em cada um de nós presentes na projeção do filme. Uma tentativa de compreensão de como a felicidade, pelo menos enquanto meta, é passível de ser alcançada. 


\section{Ethos como conduta:}

Em primeiro lugar, iremos refletir sobre o sentido da palavra ética, conforme e sua origem grega "ethos", em um de seus significados originais, enquanto "modo de ser", "caráter", "comportamento", que fundamentalmente se questionava sobre a felicidade e os meios de se atingi-la; em contraste com a posterior moral, "mos" e "mores", do latim "costume", que se fundamenta principalmente na obediência às normas, tabus, costumes ou mandamentos culturais, hierárquicos ou religiosos recebidos e feitos pela sociedade.

O termo ética, enquanto forma de comportar-se, busca encontrar um modo positivo dos seres humanos viverem em comunidade, calcado na capacidade de bem estar através da compreensão e do pensamento. Na filosofia clássica, a ética abrangia todos os campos ligados à maneira de viver. Com a posterior especialização das áreas do conhecimento, particularmente depois da Revolução Industrial, isso foi se transformando, muito embora desde a Idade Média esta noção mais normativa dos códigos éticos tenha sido bastante divulgada.

De forma bastante genérica, poderíamos dizer que hoje em dia é bastante comum se delimitar uma possível definição de ética como sendo a área que estuda o comportamento e as normas morais da sociedade, que busca entender os costumes de determinadas culturas; a diferença entre a Moral seria que, enquanto a ética tenta compreender a conduta humana, a moral estaria mais ligada aos valores atribuídos a esta, isto é, à qualidade desta conduta, onde o julgamento ganha uma maior dimensão, principalmente dentro das dicotomias "Bem e Mal”. Todavia, as noçóes de Ética e de Moral foram se tornando cada vez mais próximas. Falamos, por exemplo, em "código de ética profissional”, onde literalmente se estabelece leis de conduta para se exercer determinada profissão.

Mas neste estudo, não é sobre as regras que se quer refletir, mas sim sobre a conduta pessoal, como se através da compreensão e da busca de conhecimentos cada vez mais profundos, ou mesmo "insights" pessoais, pudéssemos ser capazes de estabelecer certos "códigos individuais de conduta" que, independentemente ou não dos códigos já estabelecidos pelas leis, fossem capazes de trazer uma vida mais significativa, compassiva e sábia para nós e que de forma direta ou indireta fosse capaz de beneficiar os outros.

Este tipo de procedimento, particularmente ligado à ética, serve como exemplo para várias áreas do conhecimento e da vida, como fica claro também no trabalho do filósofo contemporâneo Pierre Hadot. Falecido em 2010, o filósofo francês passou muitas décadas se empenhando em reler a tradição da filosofia clássica, a qual, segundo Matthew Kapstein (2001, p. 47), tenta restaurar a relação entre pensamento e ser, dentro do universo filosófico inicialmente proposto pelos gregos. Ao criar o conceito de "exercício espiritual", Hadot sugere que a filosofia vista por esta perspectiva reaparece em seus moldes originais, náo como uma construção teórica, mas sim como um método para treinar as pessoas a viverem e a verem o mundo de uma nova maneira, a filosofia serviria então como uma tentativa de transformar a humanidade. Ele afirmava ainda que um filósofo deveria ser avaliado pela maneira como vive, mais do que por aquilo que simplesmente escreve (HADOT, 1995, pp. 418-19). 
Em uma direção semelhante, que enfatiza a ética cotidiana, o cientista e monge francês Matthieu Richard (2007) tenta descrever a nossa forma de conduta de forma bastante clara. , Ele diz que as bases para a ética são extremamente simples: nada é intrinsecamente bom ou ruim, o bem e o mal existem somente em termos da felicidade ou do sofrimento que eles criam para nós mesmos e para os outros.

Se formos capazes de refletir sobre as nossas ações e, neste processo, nos tornarmos conscientes não apenas das consequências dos nossos atos, mas também do quão fundamental é o questionamento ético sobre tudo aquilo que fazemos, talvez a ideia de Hadot, de que deveríamos ser avaliados pela maneira como vivemos, mais do que por aquilo que escrevemos, pudesse ser um fator capaz de transformar não só a relação que estabelecemos com os outros, mas também de trazer um maior bem estar individual e coletivo. Este tipo de preocupação naturalmente reforçaria esta sensação de bem-estar social.

Para definir o sentido de compaixão o cineasta, filósofo e escritor buddhista ${ }^{1}$ tibetano Dzongsar Khyentse Rinpoche (2008) nós oferece uma fórmula muito simples, basta colocar os nossos pés nos sapatos dos outros. Isso é, teríamos que desenvolver a sincera capacidade de nos colocar no lugar dos outros, olhar uma situação e tentar vislumbrar não apenas nossas limitadas perspectivas em relação a uma dada situação, mas, principalmente, como outros se sentem em relação àquela circunstância. Por mais "monstruosa" que uma determinada pessoa possa parecer, é importante refletir se não seria a própria ignorância da mesma sobre as consequências de seus atos a responsável por tal procedimento. Como afirmou Sócrates, as más açôes são o resultado imediato da ignorância. Ele acreditava que as pessoas naturalmente fariam o que é bom, caso soubessem o que é certo (SAHAKIAN, 1993, pp. 32-33).

Um dos primeiros filósofos ocidentais a incentivar tanto os seus discípulos quanto os cidadãos comuns a voltar sua atenção para a condição da humanidade, e dar menos importância ao mundo exterior, ele acreditava que o conhecimento que se voltasse para as condições da vida humana deveria ser colocada no patamar mais alto das investigaçôes que pudessem ser feitas no universo do saber, sendo todas as outras áreas do conhecimento relativamente secundárias. $\mathrm{O}$ auto-conhecimento é considerado um bem essencial. Para Sócrates, se alguém quiser atingir a auto-conhecimento, deve tornar-se consciente de todos os fatos (e seu contexto) relevantes à sua existência.

Ainda segundo o filósofo, caso um criminoso estivesse verdadeiramente consciente das consequências dos seus atos, ele não cometeria nem sequer pensaria em cometer essas açóes. Qualquer pessoa que saiba o que é verdadeiramente certo, irá automaticamente se comportar em acordo com este saber. A virtude é então equiparada à felicidade. $\mathrm{O}$ homem verdadeiramente sábio saberá o que é certo, fará o que é bom, e, portanto, será feliz.

Mas, como vimos em Richard, os valores “bem e mal” não são intrínsecos aos fatos, mas sim aos resultados de sofrimento ou alegria que podem gerar, não só em termos pessoais, mas também em relação aos que nos rodeiam. 
Voltando a nossa preocupação inicial, o que então, no comportamento de Philip Gröning, chama a atenção? O cineasta declara que a ideia original de fazer o filme ocorreu-lhe em 1984, quando ainda estava na escola de cinema:

Havia terminado o meu primeiro curta-metragem e estava sob a impressão do caos e dos jogos de poder durante os trabalhos de filmagem. Queria fazer algo que me trouxesse de volta àquilo que considero o trabalho artístico. Para mim, isso significa trabalhar com verdade... Assim cheguei à idéia do convento do silêncio. E aí tudo levou muito tempo (COBERTT, 2006).

O fato do cineasta, naquela curta e intensa experiência de fazer o seu primeiro curta-metragem, imediatamente identificar como problemas aquilo que ocorria em seu meio, os "jogos de poder" e o "caos", demonstra aspectos da sua conduta e de seus questionamentos, que me parecem bastante pertinentes à perspectiva aqui apresentada. É muito comum este tipo de situação acontecer em nossas relaçóes de trabalho, para grande parte das pessoas, nas mais diversas ocasiốes - como escreveu Klauss Vianna “...a inconsciência é o que gera a mediocridade. O bailarino tem os mesmos problemas de um sapateiro" (VIANNA, 1990, p. 26) - mas, saber detectar e reagir a isso, e efetivamente buscar caminhos alternativos e capazes de nos trazer satisfação, dando continuidade aos valores que realmente acreditamos, nem sempre é a conduta mais comum; nem todos optam pela conduta mais ética. Além disso, muitas vezes o que se vê é as pessoas alimentarem aqueles sentimentos, dizendo que esta ou aquela pessoa fez isso ou aquilo, todos começam a culpar uns aos outros, em vez de efetivamente buscar outras soluçóes, e trabalhar o problema de forma a também descobrir os próprios erros, ou mesmo perceber o quão limitada é a nossa perspectiva, e não simplesmente apontar as falhas alheias.

Não foi isso que Gröning fez, ele simplesmente foi investigar outras formas de trabalhar com a natureza mesquinha dos seres humanos, como afirma Schopenhauer (2003). É importante entender que quando se fala em seres humanos, estamos incluindo a todos, inclusive a nós mesmos. Além disso, a forma como ele se comportou durante todo o processo de filmagens, evitando ao máximo fazer barulhos, efetivamente vivendo no mosteiro e se incorporando à rotina, ser a única pessoas a entrar lá e ser capaz de descartar uma equipe, não trazer equipamento de luz, o respeito em relaçáo a escolha feita pelos monges, a busca de sentido e beleza que pudesse estar ali presentes, entre tantas outras atitudes e qualidade de caráter que ali foram demonstradas, evidenciam a conduta ética do cineasta; a qual nos parece exemplar no sentido que aqui nos propomos a pensar, enquanto bússola para o fazer cinematográfico.

O cineasta manteve sempre a palavra dada aos monges e a fidelidade a si mesmo; ele não "caiu em tentação" e, ainda assim, o filme adquiriu uma dimensão muito pouco esperada, pelo menos em termos de apelo comercial - um filme de 162 minutos, praticamente todo em silêncio, apenas com os ruídos do local e algumas palavras dos monges, com nenhum tipo de luz artificial, além das velas do próprio mosteiro, etc. -, recebendo inúmeros prêmios nacionais e internacionais ${ }^{2}$ e tendo sido visto, no ano de seu lançamento, por mais de 100 mil espectadores. 
Sem estabelecer um discurso piegas sobre uma personalidade de exceção, queremos apenas tomar este exemplo do documentário feito por Gröning, para refletir sobre a importância da um tema como este - a ética no cinema e nas artes -, o qual, muitas vezes por ser visto como pouco "objetivo", ou mesmo fora do mainstream, acaba por ser negligenciado nos debates sobre cinema e das artes em geral. Como enfatiza Tchekhov, não deveria ser o artista "um ser dotado da capacidade de ver e vivenciar coisas que são obscuras para a pessoa comum" (CHEKHOV, 2010, p. 3). Poder ver e vivenciar uma situação onde a ética é o aspecto mais importante, e ser capaz de transmitir isso ao público, parece ter sido parte da proposta do cineasta, que transformou sua arte em espelho e o fez refletir sobre o seu público.

\section{Ethos como morada:}

Em segundo lugar, ao pensarmos no resgate de um outro sentido da palavra ética, ainda conforme sua origem grega "ethos", que também abrange o significado de "morada", "lugar onde se vive", e verificarmos que o filme de Gröning tem como cenário um mosteiro da ordem dos cartuxos, na grande Chartreuse dos Alpes franceses, vemos que o processo ético abordado como forma de conduta por parte do próprio documentarista, ganha mais uma camada de significação, ao investigarmos a ética também como local habitado por nós em O Grande Silêncio, quando somos convidados a coabitar com os monges cartuxos em um mosteiro que nos é mostrado através do olhar do cineasta. Ele nos transporta a uma morada onde disciplina, conduta, respeito, silêncio, dedicaçáo, entre tantas outras características, se tornam a nossa própria morada por 162 minutos.

Ao ser indagado como se faz um filme que, ao descrever um mosteiro, torna-se ele próprio um mosteiro, o cineasta responde, "Até hoje ainda não sei como, mas sei que é possível. Em um dado momento, o filme encontrou a sua forma e tornou-se um espaço e não uma narração" (CORBETT, 2006). Esta percepção do espaço como "substituto" da narrativa, revela de forma ainda mais clara a dimensão que a "morada", o "ethos", ocupa no trabalho realizado por Gröning. O filme acontece em um único local, ficamos ali, imersos, presentes em uma habitação que até então não havia sido por nós frequentada, e também penetramos neste "ethos" silencioso em um lugar similarmente desprovido de luz artificial direta (a não ser a vinda do projetor), pelo menos durante o tempo em que dura aquela sessão. Além disso, o silêncio também faz parte do ambiente da sala de cinema, o "código" ético estabelecido entre o público do filme, de forma não verbalizada, também é o de silêncio.

Assistimos às silenciosas imagens circundados pelos nossos silêncios, pelas respiraçôes, um leve ruído de um ajeitar-se na cadeira, uma tosse encoberta pelas mãos, um zíper de bolsa aberto com cuidado, um telefone móvel "distraído" desligado em um último momento. $\mathrm{O}$ local que habitamos por algumas horas para assistir o filme se mistura com aspectos do local observado, e somos como que levados a tentar desenvolver as mesmas qualidades de disciplina, conduta, respeito, silêncio e até dedicação, que os cartuxos em seu mosteiro. O "ethos" do cinema nos abriga por algumas horas e traz em seu ventre as irradiantes qualidades de uma convivência pacífica e silenciosa. Ainda que alguns possam se sentir "entediados" durante a projeção, a ética da conduta na sala os leva a permanecer ali de 
forma silenciosa, ou retirar-se como acontece com muitos dos candidatos a monges que vão até o mosteiro e, depois de algum tempo, desistem da "carreira", ou são nomeados pelos próprios integrantes a se retiraram; não por reprovação, mas simplesmente por não terem o perfil adequado para aquele estilo de vida; como aconteceria com um espectador do filme que rompesse com o acordo silencioso que é estabelecido ao se entrar na sala de cinema. Se alguém começasse a fazer barulho ou a se comportar de forma inadequada, alguém teria que pedir que ele se retirasse, caso a pessoa náo o fizesse por vontade própria. Para aqueles que aceitam o desafio, por algumas horas, sala de cinema e mosteiro se equiparam e somos convidados a estabelecer uma conduta de acordo com tais regras, mas tanto os monges como nós espectadores, na maioria absoluta dos casos, vamos até ali por vontade própria e permanecemos por vontade própria, o "ethos" enquanto local nos ajuda a caminhar de acordo com o "ethos" enquanto conduta.

Um dos seminários apresentados durante o $10^{\circ}$ Encontro da Sociedade Internacional de Etnologia e Folclore (SIEF) pela antropóloga Ana Cristina Lopes (2011), evidencia o fato de como uma pessoa é capaz de transformar um local e vice-versa, quando um determinado tipo de conduta é estabelecido como pertinente àquele espaço, depois deste ter sido de alguma forma sacralizado por uma determinada presença; mas tudo isso depende, para ser completo, da participação ativa dos envolvidos ${ }^{3}$. Este tipo de constatação evidencia mais uma vez esta relação de como o local que habitamos, a mora$\mathrm{da}$, ainda que seja por algumas horas, como no caso do filme ou mesmo do ritual, é capaz de influenciar a nossa conduta e de como estes dois sentidos da palavra "ethos" se abraçam de forma ainda mais forte.

Esta ligação entre o comportamento e o ambiente, vista de forma mais genérica - e que foi fonte de questionamentos desde o princípio dos estudos mais especializados em sociologia, antropologia, ciências políticas ou mesmo da psicologia, da filosofia e da própria biologia, onde bate-se em uma tecla bastante recorrente de como o meio é capaz de influenciar o homem e vice-versa -, é algo relativamente muito divulgado; mas este não é o ponto que se quer discutir aqui.

Também não é o caso, como pode ser verificado em determinado tipos de expressão artística como, por exemplo, o naturalismo (muitas vezes tido como reducionista), tão bem representado por Émile Zola, de se tentar criar, ou reproduzir, um retrato dito "fiel à natureza", a qual é evidenciada e expressa. Novamente, não é sobre este tipo de preocupação de que estamos falando, não é sobre uma reprodução "fidedigna" da vida no mosteiro.

Estamos nos referindo à entrada em um universo que nos é trazido pelas imagens em movimento, e que é capaz de nos transformar, que temporariamente nos desloca, nos arrebate, nos tira da zona de conforto que estávamos acostumados, e que pode nos abrir diversas perspectivas e questionamentos sobre as nossas próprias vidas e escolhas. É deste abalo causado pelas imagens, que se impóe de forma magistral através do silêncio, de que estamos falando. Náo estamos falando de um universo, de um local, pré-existente, mas sim de um processo, de um transformar-se que é proporcionado por aquele "ethos" proposto e apresentado pelo cineasta. 
A observação mais detalhada do filme nos oferece uma possibilidade de reflexão, e mesmo de transformação, sobre como nos remetermos a significação de "ethos" e seus respectivos sentidos, para que possamos ir mais a fundo na descoberta de possíveis camadas de investigação, as quais não estavam necessariamente já expostas quando começamos a assistir o filme. E é por isso que, de forma mais ou menos latente, habitamos durante a projeção do filme, ou mesmo durante a leitura destas páginas, em um espaço também físico, mas principalmente mental, que nos permite navegar por novos universos de sentido, sejam estes vividos de forma mais emocional, intelectual ou mesmo meditativa. Como se a penetração nesta dimensão tácita de nós mesmos, trazida pelo filme, fosse capaz de tornar os espectadores sensíveis à tal proposta, ao conduzí-los a um local, um ethos, até então inexplorado.

\section{Ethos como temática (ou caminho a ser percorrido):}

Em terceiro lugar, para investigar o caminho percorrido, ou a temática do filme, pensamos no sentido clássico dos estudos sobre ética que, como foi dito, fundamentalmente se questionavam sobre a felicidade e os meios de atingi-la. É interessante enfatizar que, na antiguidade, a ética era entendida como a busca do entendimento sobre as formas mais plausíveis de se alcançar a felicidade e também como uma investigação sobre o que significa a felicidade; ao longo dos tempos, a questão ética foi se equiparando às questóes mais ligadas à moral (como foi mencionado acima). Durante o Renascimento, entretanto, voltou-se a pensar novamente sobre ética como uma área de conhecimento voltada para os meios de alcançar bem estar e felicidade; hoje em dia, muitas vezes os conceitos se confundem, chegando a parecer mais uma questão terminológica, do que de "conteúdo" propriamente dito. Mas, como deve ter ficado claro, é sobre esta perspectiva ligada à investigação dos meios de se obter a felicidade, que nos referimos neste estudo.

Assim sendo, percebemos como o principal tema do filme - o trajeto percorrido, o caminho - a tentativa de entender aspectos da condição e das escolhas humanas como ferramentas que podem nos levar à felicidade. De forma similar à trajetória da própria filosofia, Gröning também nos propóe fazer esta reflexão.

O convite à contemplação não implica em uma resposta definitiva, ou única. Ao longo dos tempos, os estudos filosóficos que se preocuparam com o tema da felicidade, apresentaram respostas variadas, e sistemas filosóficos diferentes levantaram inúmeras propostas para uma compreensão específica sobre os meios de se obter felicidade; muitos se calcam na simplicidade (como Demócrito), na auto-suficiência (como os cínicos), na serenidade (como os estoicos), na ausência de julgamento (como os céticos), na capacidade de beneficiar e de Agir (como pensou Espinoza), e assim por diante. Se pensarmos em uma "questão central" relativa à ética, sobre a qual tantos se debruçaram, talvez possamos dizer que uma frase possível para resumi-la seria: Como devemos agir perante os outros e a nós mesmos para sermos capazes de "criar", ou mesmo de "sentir", felicidade? 
A busca de Gröning nos traz alguns indícios nesta direção. Ao ser indagado sobre como fora a experiência de viver entre os monges durante a rodagem, o cineasta responde que havia sido uma boa experiência, e que este era o principal motivo para haver feito esse filme. Ele diz:

No princípio, estava muito triste e solitário. Quando não se fala, a pessoa começa a refletir sobre o que faz e vem um vazio. Entáo a coisa mudou, pouco a pouco a percepção ficou bem mais clara, e tive uma sensação tranqüilizadora. Tudo o que você vê ou ouve o faz feliz como ser humano. É uma coisa curiosa: quando você consegue não ficar pensando no próximo momento, nem fazer muitos planos - é uma espécie de pura felicidade. Você fica simplesmente feliz. (COBERTT, 2006)

E, ao ser perguntado se fora difícil retornar à sua antiga vida, após deixar o mosteiro, ele fala:

Acima de tudo tomei consciência - após conviver com essas pessoas bastante livres de medos - de quanto a nossa sociedade é dirigida pelo medo. Costumamos dizer que ela é impulsionada pelo consumo e ganância, mas isso não é verdade. Ganância, consumo, o desejo de ter um novo Porsche, por exemplo, é uma máscara para o puro medo. É uma sociedade que beira o pânico, e isso foi difícil de aceitar (COBERTT, 2006).

É interessante notar que o cineasta efetivamente afirma ter tido momentos de "pura felicidade", simplesmente por estar ali, sem fazer planos, presente em cada detalhe, em cada momento; além disso, fica também evidente, que ele entra em um estado de reflexão sobre a vida, e o medo que nos envolve a todo instante. O simples prazer de estar tranquilo e livre, traz a felicidade para ele, assim como afirmava Epicuro, para quem a felicidade consiste na busca do prazer (Epicuro, 2002), que ele definia como um estado de tranquilidade e de libertação do medo (ataraxia), e de ausência de sofrimento (aponia). Para ele, a felicidade não é a busca desenfreada de bens e prazeres corporais, mas o prazer obtido pelo conhecimento, amizade e uma vida simples. Ele argumentava que ao comermos, obtemos prazer náo pelo excesso ou pelo luxo culinário (que leva a um prazer fortuito, seguido pela insatisfação), mas pela moderação, que torna o prazer um estado de espírito constante, mesmo se nos alimentarmos simplesmente de pão e água.

A experiência dos monges e do próprio Gröning parecem muito similares ao ideal de simplicidade sugerido por Epicuro. O tema do filme parece ficar ainda mais evidente através de um dos únicos momentos falados ali presentes, quando, quase ao fim da película, um dos monges diz que aquilo que eles vivem é a pura felicidade, ele diz que "...basta fazer isso (acreditar em Deus) para sermos felizes". Talvez este "isso" da frase, possa ser substituídos por muitas coisas, de acordo com a visão de cada um, mas temos novamente aqui enfatizado o caráter de caminho, de trajetória a ser percorrida, e das escolhas feitas ao longo da vida. Para os monges a opçáo parece clara, e para o cineasta uma busca em processo, a qual foi tão belamente compartilhada com o público. 


\section{Considerações finais}

Como foi sugerido no início deste texto, ao se pensar na cartografia como uma forma de orientação aos navegadores, mais do que um desenho preciso dos contornos do cinema mundial, este breve estudo faz uma reflexão e se utiliza da ética com o sentido de bússola. Acreditamos que o filme O Grande Silêncio, juntamente com o seu realizador, mostram-nos uma forma de viver e agir que parece pertinente ao trilhar ético tal qual aqui enfatizado, através da conduta, do próprio ambiente que criamos e vivemos e do caminho que escolhemos percorrer.

De uma forma ou de outra, todos nós, seres humanos, estamos em busca da felicidade, a forma como buscamos atingí-la é que parece ser bastante variável. Talvez a remoção da ignorância, como afirmou Sócrates, que nos impede de agir de forma ética, e também a simplicidade, como retratada por Epícuro, possa nos levar a alguns indícios de como proceder para que isso possa acontecer de forma individual e coletiva.

Deixamos aqui apenas relatado algumas impressóes de uma proposta cinematográfica e ética que nos parece pertinente a esta nova bússola cartográfica, querer efetivamente trilhar passos similares, ou seguir tal orientação, fica a critério de cada um.

\section{Referências bibliográficas}

CHEKHOV, Michael. Para o Ator. Tradução Álvaro Cabral. São Paulo: Martins Fontes, 2010 (primeira edição brasileira 1986).

EPICURO. Carta sobre a felicidade (a Meneceu). Tradução e apresentação de Álvaro Lorencini e Enzo Del Carratore. São Paulo: UNESP, 2002 (2a edição). HADOT, Pierre. Quiest-ce que la philosophie antique? Paris: Gallimard, 1995.

KAPSTEIN, Matthew T. Reason's Traces. Identity and Interpretation in Indian and Tibetan Buddhist Thought. Boston: Wisdom Publications, 2001.

KEOWN, Damien (). The Nature of Buddhist Ethics. London: Palgrave, 2006.

KHYENTSE, Dzongsar Jamyang. What makes you not a Buddhist. Boston \& London: Shambhala, 2008.

LOPES, A. C. Performance and Text in the Making of Tashiding (Sikkin, India) as a Power Place. Apresentado na 10a SIEF (Sociedade Internacional de Etnologia e Folclore), realizado em Lisboa entre 17 a 21 de Abril de 2011.

RICARD, Matthieu. Happiness: A Guide to Developing Life's Most Important Skill. NY, Boston, London: Little, Brown and Company (Hachette Book Group), 2006.

SADDHATISSA, H. Buddhist Ethics. London: George Allen \& Unwin, 1970.

SAHAHIAN, William S. \& SAHAKIAN, Mabel Lewis. Ideas of the Great Philosophers. New York: Barnes \& Noble Books, 1993. 
SCHOPENHAUER, Arthur. A Arte de Insultar. São Paulo: Martins Fontes, 2003.

TURNER, Victor. From Ritual to Theatre: The Human Seriousness of Play. New York, Paj Publications, 1982.

VIANNA, Klauss. A Dança. São Paulo, Ediçóes Siciliano, 1990.

\section{Filmografia}

Die Grosse Stille (O Grande Silêncio) (2005) Dir. Philip Gröning, Alemanha.

\section{Website}

CORBETT, Deanne. Silêncio dos monges vira sucesso de bilheteria. 2006. Disponível em: http://www.dw.de/dw/article/0,,1890158,00.html .

\section{Nota}

1. A termo "buddhista", muito embora conste do dicionário com apenas um "d" e sem o "h" (isto é, budista), é originário da palavra Buddha em sânscrito, que é composta pelas sílabas Bud + Dha, a palavra sem estes duas letras teria outro significado. É importante lembrar que estamos tratando de um termo estrangeiro, e a mera adaptação fonética, em termos de sonoridade, não é o suficiente para nos remeter ao sentido original da palavra. Uma explicaçáo mais detalhada sobre o assunto poderá ser encontrada brevemente em meu livro "Como Ler Filosofia Buddhista" a ser lançado pela editora Paulus em 2014.

2. Entre eles: Prêmio Especial de Juri no Festival de Sundance (2006); Prêmio de filme Europeu na categoria documentário (2006); Melhor documentário no Festival de cinema da Bavária (2006); Prêmio da associação de críticos de cinema da Alemanha, como melhor documentário (2006); Prêmio dos críticos de cinema da Alemanha, também como melhor documentário (2006); Prêmio de melhor Câmera da Alemanha, melhor direção de câmera em documentários (2006); Na Itália recebeu o prêmio internacional Ennio Flaiano por melhor filme e melhor direção de fotografia.

3. Ao falar de Tashiding, na Índia, autora escreve: "The keyword here is experience, or better yet the sharing of experience. Indeed, the nature of a place like Tashiding can only be fully grasped through a personal experience, which "would be incomplete," recalling here Victor Turner, "unless one of its 'moments' is performance."

4. Uma discussão mais delongada sobre o tema pode ser visto no já citado: "Ideas of the Great Philosophers". 